\title{
CYBEREDUCACIÓN: DISCUTIR EL HABITUS DE LOS PROFESSORES EN UN CONTEXTO DE PRODUCCIÓN DE ACTIVIDADES-MATEMÁTICAS-CON- MEMES
}

\author{
Andréia Luisa Friske \\ andreiafriske@gmail.com \\ https://orcid.org/0000-0002-1977-129X \\ Secretaria de Educação do Estado do Rio Grande do Sul \\ Porto Alegre, Brasil. \\ Maurício Rosa \\ mauriciomatematica@gmail.com \\ https://orcid.org/0000-0001-9682-4343 \\ Universidade Federal do Rio Grande do Sul (UFRGS) \\ Porto Alegre, Brasil.
}

Recibido: 29/agosto/2021 Aceptado: 06/setembro/2021

\begin{abstract}
Resumen
Este artículo tiene como objetivo investigar cómo se muestra la Ciberformación con los profesores que enseñan matemáticas, en términos pedagógicos, cuando se insertan en el proceso de producción de actividadesmatemáticas-con-memes. El Cyberformación se caracteriza por ser una forma/acción con docentes que entiende las Tecnologías Digitales como partícipes del proceso de constitución del conocimiento matemático. Para obtener posibles respuestas para esta investigación, dos docentes que participaron en el curso de extensión denominado "¿Quieres memetizar? Construyendo actividades-matemáticas-con-memes" ofrecidas a los profesores que enseñan matemáticas, en la región metropolitana de Porto Alegre, en el estado de Rio Grande do Sul (Brasil). Ciertos habitus que cuando se confrontan, en un campo, con el concepto de Ciberformación, permitió una reflexión sobre estas prácticas, caracterizadas por la violencia simbólica y una posible transformación de prácticas.
\end{abstract}

Palabras clave: Educación Matemática; Meme de Internet; Habitus; Tecnologías Digitales; Formación con profesores.

\section{CYBEREDUCATION: DISCUSSING THE HABITUS OF TEACHERS IN A CONTEXT OF MATHEMATICAL-ACTIVITIES-WITH-MEMES PRODUCTION}

\begin{abstract}
This article aims to investigate how Cybereducation with mathematics teachers is shown, in pedagogical terms when they are inserted in the production process of mathematical-activities-with-memes. Cybereducation is characterized as a form/a(c)tion with teachers that understand Digital Technologies as participants in the process of constitution of mathematical knowledge. We obtained possible answers for this research from two teachers who participated in the extension course called "Do you want to memetize? Building mathematicsactivities-with-memes" offered to teachers who teach mathematics, in the metropolitan region of Porto Alegre, in the state of Rio Grande do Sul (Brazil). In this investigation we can evidence that the analysed practices of teachers were showed from certain habitus that when confronted, in a field, with the concept of Cybereducation, allowed a reflection on these practices, featuring symbolic violence and a possible transformation of practices.
\end{abstract}

Keywords: Mathematics Education; Internet Meme; Habitus; Digital Technologies; Teacher Training. 


\title{
CYBERFORMAÇÃO: DISCUTINDO O HABITUS DE PROFESSORAS EM UM CONTEXTO DE PRODUÇÃO DE ATIVIDADES-MATEMÁTICAS-COM-MEMES
}

\begin{abstract}
Resumo
Este artigo tem o objetivo de investigar como se mostra a Cyberformação com professoras que ensinam matemática, em termos pedagógicos, quando elas se inserem no processo de produção de atividadesmatemáticas-com-memes. A Cyberformação é caracterizada como uma forma/ação com professores/professoras/professories ${ }^{1}$ que compreende as Tecnologias Digitais como partícipes do processo de constituição do conhecimento matemático. Para obter possíveis respostas para essa pesquisa foram analisadas duas professoras que participaram do curso de extensão denominado "A fim de memetizar? Construindo atividades-matemáticas-com-memes" ofertado para professores/professoras/professories que ensinam matemática, na região metropolitana de Porto Alegre, no estado do Rio Grande do Sul. Nessa investigação foi possível evidenciar que as práticas das professoras analisadas se mostraram enraizadas em determinados habitus que quando confrontados, em um campo, com a concepção de Cyberformação permitiram uma reflexão sobre estas práticas, caracterizando uma violência simbólica e uma possível transformação de práticas.
\end{abstract}

Palavras-chave: Educação Matemática; Meme da Internet; Habitus; Tecnologias Digitais; Formação com professores.

\section{Introdução}

O meme da internet pode ser compreendido como "[...] uma unidade de informação (ideia, conceito ou crença), que se reproduz pela transmissão via internet (e-mail, chat, fórum, redes sociais, etc.) na forma de um hiperlink, vídeo, imagem ou frase. Pode ser passado como uma cópia exata ou pode mudar e evoluir" (Díaz, 2013, p. 97). Também, nesse sentido, conforme Harringhton Martínez \& Díaz Blanca \& Bolívar Orellana (2020, p. 841)2, os memes:

Apesar da heterogeneidade terminológica, em geral, são considerados como peças de conteúdo com vários formatos (imagem estática, macroimagem, GIF animado, vídeos de transmissão em massa, música, frases surpreendentes, colagens, pinturas, modas, fotografias) que são produzidos e consumidos massivamente pelas redes sociais, graças à utilização de múltiplos aplicativos e programas de edição, basicamente para fins de entretenimento.

Dessa maneira, o meme é composto por imagens, vídeos e textos que tendem a viralizar $^{3}$ pela internet, isto é, se propagar rapidamente pelas redes sociais como o WhatsApp, Facebook, Twitter ou Instagram (Friske, 2020). Podemos, então, considerar que os memes tem um alcance global, não apenas pelo advento da internet, por meio da qual, em

\footnotetext{
${ }^{1}$ Utilizamos esta grafia para empoderar todos os gêneros neste artigo. Logo, inserindo o gênero gramatical neutro (Cassiano, 2019) ao masculino e feminino, estamos nos posicionando politicamente em acordo às concepções de combate à exclusão, defendidas pela concepção da Cyberformação (Rosa, no prelo, n.d.).

2 "A pesar de la heterogeneidad ter minológica, en general, se consideran como piezas de contenido con diversos formatos (imagen fija, imagen macro, GIF animado, videos de difusión masiva, música, frases sorprendentes, collages, pinturas, modas, fotografias) que se producen y consumen massiva mente por las redes sociales, gracias al empleo de múltiples aplicaciones y programas de edición, con un fin básicamente de entretenimento".

3 "Tornar viral; fazer com que algo seja compartilhado por um grande número de pessoas, especialmente em redes sociais, por exemplo, o vídeo viralizou" (Dicio, 2021).
} 
questão de segundos, é possível alcançar pessoas em qualquer parte do mundo, mas, pela sua linguagem e pelo seu contexto. Assim, os memes acabam se tornando uma alternativa à comunicação e ao envio de informações às pessoas.

Nos direcionando para o campo da educação matemática, compreendemos que o meme pode atuar como um possível recurso pedagógico para as aulas, ou seja, pode tornarse um meio de possibilitar a constituição do conhecimento matemático. Compreendemos, então, que os memes podem tornar-se partícipes dessa constituição e não apenas um suposto recurso de motivar os alunos e as alunas ou de tornar a aula "diferente". Nessa perspectiva, pensamos na Cyberformação com professores/professoras/professories que ensinam matemática, a qual vislumbra o trabalho com Tecnologias Digitais (TD) de modo a considerar as TD como fator proeminente dessa formação, isto é, “[...] como figura que se apresenta, são meios que interferem significativamente no processo cognitivo e/ou formativo de modo a ampliá-los ou potencializá-los" (Rosa, 2018, p. 258). Nesse contexto, pensamos em atividades-matemáticas-com-memes que assumem os memes como partícipes do processo de constituição do conhecimento matemático e, desse modo, são atividades que não são realizadas sem os memes ou que sem esses, não produziriam o mesmo sentido matemático para o que objetivaram. Destarte, são atividades-matemáticas-com-TD (Rosa \& Mussato, 2015) e, devido a isso, escrevemos atividades-matemáticas-com-memes utilizando o hífen, pois essas atividades são pensadas e articuladas com a projeção do movimento intencional dos/das/des estudantes em relação aos memes com a matemática.

Adentramos, então, na questão diretriz desse artigo: "Como se mostra a Cyberformação com professoras que ensinam matemática, em termos pedagógicos, quando elas se inserem no processo de produção de atividades-matemáticas-com-memes?". Para descrever possíveis respostas para essa questão, de forma qualitativa, analisamos a participação de duas professoras em um curso de extensão denominado "A fim de memetizar? Construindo atividades-matemáticas-com-memes" ofertado para professores/professoras/professories que ensinam matemática, na região metropolitana de Porto Alegre, no estado do Rio Grande do Sul. Esse curso de extensão teve por objetivo trabalhar e desenvolver atividades-matemáticas-com-memes tornando possível observar todos os processos de produção dessas atividades, ou seja, todas as discussões presenciais, as orientações, as conversas, os planejamentos pelo WhatsApp, o desenvolvimento das atividades nas escolas e o compartilhamento das experiências durante o curso.

Desse modo, vislumbrar a formação com professoras que ensinam matemática provém da própria dinâmica do curso, a qual se embasa na concepção de Cyberformação. 
Ou seja, não é uma formação para professores ou de professores, mas "com" professores/professoras/professories, de modo que esses/essas/essus decidem em conjunto com os/as/es formadores/formadoras/formadories os tópicos matemáticos a serem investigados, o ano de ensino que se dedicarão as atividades, o que fazer, como fazer e para que fazer.

Discutiremos, então, a concepção denominada Cyberformação com professores/professoras/professories que ensinam matemática, enfocando, principalmente, sua dimensão sociológica por meio da discussão de habitus, campo e violência simbólica levantada por Bordieu (1983, 2009, 2012) e Bordieu e Passeron (2014), entre outros teóricos.

\section{Referencial Teórico}

Conforme Rosa (2015), a Cyberformação nos traz as ideias de "Cyber" e "formação". A primeira ideia, "Cyber", remete-nos ao trabalho com TD que não se caracteriza como uso pelo uso, mas que concebe as TD como partícipes da constituição do conhecimento. A segunda, "formação", assume a concepção de forma/ação como a ação (artística e plástica) que formata a imagem, que realiza o movimento e a fluidez atuante na forma (Bicudo, 2003), ou seja, ação constituinte do "ser" que se mostra e assume a figura professor/professora/professorie de matemática ou que ensina matemática. Nossa forma/ação, então, muda e evolui constantemente, outras vezes regride para, então, se transformar e avançar novamente, representando um processo de constante metamorfose. Assim,

[...] consideramos a Cyberformação como uma formação que envolve o uso de recursos tecnológicos didáticos, mas não como uma "formação ideal" e nem como sendo uma formação "melhor" ou "pior" que outras, mas como uma concepção diferenciada e que possa abrir horizontes pedagógicos pelos quais seja possível desenvolver atividades educacionais, $[. .$.$] [constituindo] conhecimento matemático em$ sintonia com o mundo. Uma formação que considera o professor/aluno como também um usuário de TD, que, ao fazer uso destas, também se forma ao experimentar, descobrir as inúmeras e infinitas possibilidades que a tecnologia permite à sua formação contínua e nunca finalizada. (Vanini, Rosa, Justo \& Pazuch, 2013, p. 161)

Desse modo, a Cyberformação abrange diferentes dimensões nesse processo de formar-se, por exemplo a dimensão matemática, pedagógica, tecnológica, social, política, estética, cultural, filosófica, etc. Nessa perspectiva, destacaremos a dimensão pedagógica e a dimensão sociológica da Cyberformação, mas consideramos que essas dimensões não são estanques, isto é, elas “[...] são caracterizadas por uma totalidade entre elas, 'misturando-se' umas com as outras, como se fossem três [ou mais, na verdade, várias] tintas de diferentes 
cores" (Vanini, 2015, p. 74) em fluxos coloridos que se entrecruzam, conectam, misturam e transformam.

Compreendemos que, na perspectiva da dimensão pedagógica, é possível mobilizar reflexões sobre as concepções de ensino e de aprendizagem de professores/professoras/professories de matemática, considerando que essas concepções são resultantes dos processos vividos por esse/essa/essu professor/professora/professorie em sua formação inicial ou continuada (Pazuch, 2014). Conforme Rosa (2015), é necessário refletir, principalmente, a respeito do design de atividades, da utilização dos recursos tecnológicos e dos diferentes processos educativos matemáticos.

Inicialmente, pensa-se nas inter-relações que ocorrem, a distância e presencialmente por meio desses recursos digitais, e em como tais materiais podem transformar/potencializar a [...] [constituição] do conhecimento matemático; e, posteriormente, busca-se que cada professor ou futuro professor desenvolva o próprio material em consonância com esse processo reflexivo. (Rosa, 2015, p. 69-70)

Nesse âmbito, almejamos práticas docentes que não tem o intuito de apenas reproduzir atividades já realizadas sob uma nova roupagem, isto é, utilizando os recursos tecnológicos apenas para dar um "novo colorido" (Rosa, 2018). Entendemos que "[...] olhar para aspectos pedagógicos pressupõe dialogar e questionar as construções teóricas ou referências presentificadas no discurso e na ação docente do[da/de] professor[professora/professorie] de matemática, que, agora, deseja ensinar com TD" (Pazuch, 2014, p. 49). Dessa maneira, a forma/ação não é estagnada e fixa, ela está em constante transformação, refletindo sobre o trabalho com TD.

No decorrer dos processos de desenvolvimento de atividades-matemáticas-com-TD, no caso, -com-memes, por exemplo, damos ênfase neste artigo à dimensão pedagógica e dessa forma é possível retratar diferentes práticas de desenvolvimento dessas atividades. Essas diferentes práticas assumem nuances de práticas de sala de aula, ou seja, senso prático (Bourdieu, 2009) e permitem desvelarmos indícios de habitus (Bordieu, 2009) dos/das/des professores/professoras/professories. Assim, para refletirmos sobre esses indícios em uma perspectiva sociológica, assumindo-a como dimensão da Cyberformação e entrelaçada à dimensão pedagógica, discutiremos, de antemão, a diferença entre hábito e habitus.

De acordo com o dicionário Abbagnano (2007), o termo hábito pode ser entendido considerando-o como "[...] o mesmo que costume. Em geral, a repetição constante de um acontecimento ou de um comportamento, devido a um mecanismo de qualquer gênero" (Abbagnano, 2007, p. 494). Dessa maneira, o termo hábito é vinculado a essa noção, 
relacionando o termo com a ideia de costume e de repetição de uma determinada ação ou comportamento.

Nesse contexto, Bourdieu $(2009,2012)$ trata o termo habitus de modo que esse não se confunda com essa ideia tradicional e mais geral de hábito, pois considerava necessário evidenciar as características "[...] criadoras, activas, inventivas do habitus e do agente (que a palavra hábito não diz), embora chamando a atenção para a ideia de que este poder gerador não é de um espírito universal, de uma natureza ou de uma razão humana [...], mas sim o de um agente em acção" (Bourdieu, 2012, p. 61). Conforme Bourdieu (2012, p. 61), habitus "[...] é um conhecimento adquirido e também um haver, um capital (de um sujeito transcendental na tradição idealista) o habitus, a hexis, indica a disposição incorporada".

Não obstante, segundo Vanini (2015), a concepção de habitus vincula-se a um indivíduo que age segundo uma reflexão inicial por ele estabelecida e esse ato de assumir uma posição inicial é o que o diferencia da simples ideia de hábito. Por exemplo, uma professora que utiliza o livro didático em suas aulas todos os dias. Se a questionarmos o motivo de usar sempre o livro e ela responder que nunca havia parado para refletir sobre isso e que usa por usar, temos caracterizado um hábito da professora. Neste caso, um hábito similar ao ato de escovar os dentes desde a infância, pois, por vezes, mesmo sem saber o porquê, o fazemos, tomamos por hábito escová-los todos os dias.

Entretanto, se assumirmos uma postura de escovar os dentes pelo motivo de beneficiar a saúde bucal, mesmo sem uma reflexão profunda sobre isso, assim como, se a professora responder que utiliza o livro didático por conter bons exercícios para aprender matemática, pois só é possível aprender matemática resolvendo exercícios e utilizando o livro didático, então, há a constituição de um habitus. Apesar de usar o livro todos os dias, a professora já passou por um processo reflexivo inicial, ou seja, por meio da disposição a ensinar, criou uma postura educacional, uma disposição a utilizar o livro didático como um recurso pedagógico, para ela, eficiente. Isto é, ela assumiu uma postura didática e acredita que o livro didático e os exercícios são necessários para os/as/es alunos/alunas/alunes aprenderem matemática, assim, se constituiu um habitus da professora em ensinar matemática por meio do livro, o qual é assumido por vários outros/outras/outres professores/professoras/professories.

Dessa forma, podemos dizer que o habitus “[...] está ligado diretamente à cultura, à história e à representação social do indivíduo, sendo constituído a partir de um caminho realizado por ele na sociedade, um produto que começa a fazer parte da sua história e que se torna algo constituído com o indivíduo" (Vanini, 2015, p. 87). Por exemplo, podemos pensar 
em um/uma/ume professor/professora/professorie que sempre dá aula expositiva com quadro e giz e, mesmo após ter à disposição internet e poder utilizar diferentes recursos, continua exatamente com a mesma aula por acreditar que essa é a maneira correta de dar aula. Nesse caso, apesar do/da/de professor/professora/professorie ter à disposição diferentes recursos este/esta/estu acredita que a forma expositiva é o único modo de ensinar seus/suas/sues alunos/alunas/alunes, pois, foi dessa maneira que lhe foi ensinado e, assim, assume essa postura. Nesse contexto, “[...] o habitus pode ser entendido como um sistema de disposições impregnadas no indivíduo, em que os modos de perceber, de sentir, de fazer, de pensar são conduzidos por ações próprias, inerentes a uma condição arbitrária" (Vanini, 2015, p. 89).

Também, entendemos, conforme Bourdieu (2009), que cada um/uma/ume aprende desde a infância e esse conhecimento constituído com a prática acaba sendo transformado em um sistema de disposições para a ação. O autor afirma que "[...] o habitus, como toda arte de inventar, é o que permite produzir práticas em número infinito, e relativamente imprevisíveis" (Bourdieu, 2009, p. 92). Além disso, o habitus é o responsável por produzir as práticas tanto individuais como coletivas, pois ele é produto da história e “[...] garante a presença ativa das experiências passadas que, depositadas em cada organismo sob a forma de esquemas de percepção, de pensamento e de ação, tendem [...] a garantir a conformidade das práticas e sua constância ao longo do tempo" (Bourdieu, 2009, p. 90).

Compreendemos que o habitus está entrelaçado com as vivências e experiências de professores/professoras/professories e, portanto, está relacionado com as suas práticas. Desse modo, conforme Vanini (2015, p. 98), “[...] a manutenção de habitus é um fator forte e, para que ocorra uma alteração, um desequilíbrio é necessário". Essa manutenção de um habitus é abordada, por Bourdieu (2009), por meio do termo histeresis de um habitus.

Segundo o dicionário Dicio (2021), histerese pode ser entendida, no contexto da física, como o aparecimento de um atraso na evolução de um fenômeno físico com relação a outro. Nesse sentido, podemos entender a histeresis de um habitus como "[...] uma tendência de um determinado habitus a se conservar no sujeito, mesmo que as condições objetivas que o construíram, e que estão nele refletidas, conduzam a uma transformação" (Vanini, 2015, p. 100-101). Assim,

[...] o habitus possui uma tendência natural/espontânea para se reproduzir e isso pode causar dificuldades em alguns indivíduos em construir práticas correspondentes a essa 'nova' ordem desencadeada pelo habitus. Dessa forma, para Bourdieu $(2007,2012)$, a histerese foi um termo empregado para indicar uma incompatibilidade entre um habitus e mudanças nas regularidades de um campo. (Vanini, 2015, p. 102) 
Voltando ao exemplo da professora que utiliza o livro didático todos os dias como ação de um habitus, ou seja, uma ação assumida por ela como atitude, disposição a ensinar desse modo, sob uma crença/afirmação que infere sobre o que ela faz e como faz, permite que a professora tome o uso do livro didático acreditando que apenas se aprende matemática resolvendo exercícios que esse livro contenha. Além disso, essa crença/afirmação da professora faz com que esse habitus se mantenha até que um desequilíbrio venha a acontecer em sua experiência docente. Esse habitus constituído na história dessa professora não vai ser mudado "do dia para a noite", pois uma transformação de habitus passa por um processo intenso de reflexão e consciência. Dessa maneira, suponhamos que essa professora se depare com as ideias da Cyberformação, por exemplo, que não defende um ensinar e um aprender matemática baseados necessariamente em resolução de exercícios e uso do livro didático. Logo, possivelmente, será criado um conflito. Nesse âmbito, pode ser que ocorra uma disputa de dois movimentos em relação aos objetivos envolvidos no ensinar e no aprender matemática, assim, esse conflito/disputa são condicionantes do que Bourdieu (2009, 2012) chama de campo.

Nesse sentido, segundo Bourdieu (2012), o habitus contribui para determinar um campo dotado de sentido e de valor. Além disso, para Bourdieu (1983, p. 89), os campos podem ser entendidos como "[...] espaços estruturados de posições (ou de postos) cujas propriedades dependem das posições nestes espaços, podendo ser analisadas independentemente das características de seus ocupantes (em parte determinadas por elas)". Ou seja, para que um campo funcione é necessário que existam “[...] objetos de disputas e pessoas prontas para disputar o jogo, dotadas de habitus que impliquem no conhecimento e no reconhecimento das leis imanentes do jogo, dos objetos de disputas" (Bourdieu, 1983, p. 89). Assim, um campo se caracteriza pelo embate, isto é, por ocorrer uma discussão de diferentes pontos de vista sobre determinado assunto, como por exemplo uma disputa teórica ou metodológica em um campo científico.

De acordo com Bourdieu (1983, p. 93), “[...] o campo ou, mais exatamente, o habitus de profissional previamente ajustado às exigências do campo (por exemplo, à definição da problemática legítima que esteja em vigor) vai funcionar como um instrumento de tradução". Por exemplo, conforme o autor, ser filósofo representa dominar o que é necessário em relação a história da filosofia para, então, saber se portar como filósofo no interior do campo filosófico. Desse modo, podemos dizer que há “[...] uma relação inconsciente entre um habitus e um campo" (Bourdieu, 1983, p. 93). 
Nesse contexto, temos ainda que "[...] a luta simbólica pode estabelecer relações entre indivíduos nas mais variadas classes sociais e isso pode romper com concepções antigas e constituir novas concepções" (Vanini, 2015, p. 109). Essas lutas simbólicas, que ocorrem em um campo, são originadas por determinações dos chamados detentores do poder e, então, essas determinações são constituídas por uma violência simbólica (Vanini, 2015).

Para passarmos a compreender a concepção de violência simbólica, inicialmente, definimos o termo violência. O dicionário Abbagnano (2007, p. 1002) entende violência como uma "[...] ação contrária à ordem ou à disposição da natureza" ou ainda uma "[...] ação contrária à ordem moral, jurídica ou política”. Essas concepções referem-se a cometer ou sofrer algum tipo de violência. Dessa maneira, entendemos que violência não se refere estritamente ao contexto “[...] que causa 'dano’ físico nos indivíduos, mas como aquela que gera consequências culturais, de ordem social, mesmo sendo exercida em agentes de forma simbólica" (Vanini, 2015, p. 112). Podemos pensar que os conflitos simbólicos que representam as relações de poder têm por objetivo impor uma certa visão de mundo conforme seus interesses (Vanini, 2015).

Desse modo, dizemos que “[...] toda ação pedagógica é objetivamente uma violência simbólica enquanto imposição, por um poder arbitrário, de um arbitrário cultural" (Bourdieu \& Passeron, 2014, p. 26). Por exemplo, no momento em que desenvolvemos nossas aulas, seja utilizando livro didático, listas de exercícios ou recursos tecnológicos, estamos impondo algo aos estudantes, visto que, na maior parte das vezes, não os questionamos se é isso o que eles desejam. Então, toda ação pedagógica acaba violentando simbolicamente se for abordada em um contexto de imposição, pois, de acordo com Bourdieu e Passeron (2014, p. 36-37), “[...] as relações de força determinam o modo de imposição característica de uma ação pedagógica”.

Nessa perspectiva, voltamos novamente ao exemplo da professora que sempre utiliza o livro didático e que se deparando com a concepção de Cyberformação, uma forma/ação com professores/professoras/professories que entende as TD como partícipes da constituição do conhecimento matemático, acaba entrando em conflito, pois essa concepção "bate de frente" com o que ela acredita. Nessa disputa, haverá a mudança de habitus somente se ocorrer uma violência simbólica que, nesse caso, é representada por ações educacionais, posturas, disposições, posturas que a concepção de Cyberformação defende, visto que esse constructo trabalha com a ideia de dar autonomia para professores/professoras/professories desenvolverem e produzirem suas próprias atividades e não ficarem apenas na reprodução de materiais e ideias já prontas. Assim, conforme Vanini (2015, p. 116), “[...] defendemos 
que o ensino de matemática também não precisa ter um caráter fixo, estático, ser simplesmente um algoritmo invariável a ser seguido por todos, mas que cada educador possa refletir e pensar sobre como é possível construir suas práticas de acordo com seu contexto social". Dessa maneira, a Cyberformação pode ser caracterizada como uma violência simbólica e pode acabar desencadeando “[...] uma possível transformação em sua própria forma/ação, em que o participante da formação possa saber-fazer, que possa pensar, refletir e agir com as TD” (Vanini, 2015, p. 118).

\section{Aspectos Metodológicos}

Essa pesquisa é de caráter qualitativo visto que "Enquanto os métodos quantitativos supõem uma população de objetos comparáveis, os métodos qualitativos enfatizam as particularidades de um fenômeno em termos de seu significado para o grupo pesquisado" (Goldenberg, 2004, p. 49-50). Estamos interessados em investigar o processo de desenvolvimento de atividades-matemáticas-com-memes. Queremos, então, valorizar o processo e não apenas obter um resultado numérico ou uma única resposta.

Assim, a questão diretriz desse artigo é: “como se mostra a Cyberformação com professoras que ensinam matemática, em termos pedagógicos, quando elas se inserem no processo de produção de atividades-matemáticas-com-memes?". Nesse contexto, temos o intuito de tentar responder o "como" dessa questão com indícios, pois, compreendemos que não é possível obter uma resposta final ou acabada. Além disso, o "se mostra" é no sentido do que acontece nesse processo quando, na perspectiva da dimensão pedagógica, essas professoras estão imersas em um ambiente de produção de atividades-matemáticas-commemes e ao estarem em forma/ação, estão sociologicamente articuladas frente a uma concepção educacional que pode ou não ser consonante e estruturar seu habitus formativo.

Para obter possíveis respostas para a questão de pesquisa, analisamos duas professoras $^{4}$ que participaram do curso de extensão denominado "A fim de memetizar? Construindo atividades-matemáticas-com-memes" ofertado na região metropolitana de Porto Alegre, no estado do Rio Grande do Sul. O curso ocorreu no ano de 2019, foi constituído por sete encontros presenciais e, também, por momentos a distância. O curso teve como principal objetivo trabalhar atividades-matemáticas-com-memes com professores/professoras/professories, além de propor o desenvolvimento de suas próprias

\footnotetext{
${ }^{4}$ As professoras assinaram o termo de consentimento livre e esclarecido, estando cientes da pesquisa e do uso de seus dados para futuros artigos. As autorizações dessas participantes estão e permanecerão guardadas por no mínimo cinco anos.
} 
atividades para serem abordadas com seus respectivos/respectivas estudantes em sala de aula. Além disso, foram propostas leituras de artigos e discussões sobre alguns referenciais teóricos, os quais tratavam, por exemplo, de memes da internet e Cyberformação.

Nesse contexto, entre os participantes dessa pesquisa (no total 18 participaram e concluíram o curso de extensão), estão as professoras Carla e Pamela, ambas graduadas em Licenciatura em Matemática. Elas atuam na mesma escola da rede estadual, na cidade de Novo Hamburgo, Rio Grande do Sul.

Além disso, configuram o recorte trazido neste artigo, pois, conforme Goldenberg (2004, p. 14), "Na pesquisa qualitativa a preocupação do pesquisador não é com a representatividade numérica do grupo pesquisado, mas com o aprofundamento da compreensão de um grupo social", ou seja, visamos uma investigação minuciosa em relação a cada participante e não nos preocupamos em obter uma quantidade específica e/ou expressiva de sujeitos.

Os dados do curso de extensão foram compostos por discussões gravadas em áudio e vídeo, durante os encontros presenciais, e por conversas no aplicativo WhatsApp. A escolha dos excertos discutidos e analisados nesse artigo foi realizada por meio de uma leitura de todos os registros do curso (transcrições dos áudios e vídeos e conversas do WhatsApp) buscando indícios para responder à questão diretriz. Os indícios foram destacados e agrupados evidenciando, por exemplo, o que aqui apresentamos.

\section{Descrição e Análise dos dados}

Os dois excertos que vamos analisar abordam discussões das professoras Carla e Pamela no sexto e sétimo encontro presencial, ou seja, essas discussões ocorreram nos dois últimos encontros do curso de extensão, no momento em que estavam planejando e construindo atividades-matemáticas-com-memes para as desenvolverem em suas aulas.

Para otimizar a organização dos excertos, no decorrer das transcrições de áudio e vídeo utilizamos o símbolo [...] para suprimir algum trecho do diálogo que é impertinente ou irrelevante à análise. Além disso, quando for necessário acrescentar algum comentário ou esclarecer alguma fala envolvemos o [texto entre colchetes]. Além disso, para esse artigo, selecionamos excertos que na leitura dos dados emergiram como possíveis respostas à questão diretriz desse estudo.

O primeiro excerto "Impresso ou Digital?" ocorreu no sexto encontro presencial em que a discussão foi gravada em áudio, da qual foram transcritas as informações a partir de 1 (um) minuto e 57 segundos de gravação até os 8 minutos e 55 segundos. Nesse excerto 
apresentamos uma discussão das participantes Carla e Pamela, com intervenções de Maurício (formador no curso), sobre o desenvolvimento das atividades-matemáticas-commemes. A discussão foi em torno de como trabalhar com essas atividades: por meio de material impresso ou de forma digital.

\section{Impresso ou Digital?}

[00:01:57.00] Carla: a Pamela fez um plano de aula [piloto], dai dá pra primeiro a gente usar um meme pra passar a informação e tentar extrair deles o conteúdo em si, né? [...] Daí, no caso a Pamela, ela usou os memes que a gente tinha produzido e ela questionou os alunos sobre [o meme]. [00:02:36.13] Maurício: ah já usaste?

[00:02:38.18] Carla: ela fez em uma escola!

[00:02:39.23] Pamela: eu fiz numa outra escola, não na que eu vou fazer essa atividade [referindose a proposta que o grupo estava planejando].

$[\ldots]$

[00:04:36.01] Carla: só que dai assim, a única coisa que nós estávamos falando é que ela [Pamela] imprimiu isso, né? Dai a Andréia sugeriu de usar na internet, mas é que primeiro, pra instruir tem que meio que passar...

[00:04:48.04] Pamela: é, eu apliquei em outra escola que eu tenho duas [turmas]. Ai eu só primeiro dei pra eles, eu não tive o retorno, porque terminou a aula e eles ficaram fazendo ainda. Mas a minha ideia era justamente dar a atividade pra eles fazerem e, na última questão, perguntar como eles fariam, que é quando eu propus pra eles criarem o [meme] deles, né? Eu não falei do celular, só falei pra um aluno: ah, vocês podem fazer no celular. Eu queria ver o que eles iam fazer, sabe.

[...]

[00:07:38.02] Maurício: veja essa discussão que vocês começaram, é interessante! Imprimir ou usar no celular, o que vocês acham? [referindo-se ao modo de desenvolver os memes com os alunos]

[00:07:51.01] Carla: é que a ideia é seguinte, oh professor, que eu penso o seguinte: que pra, primeiramente, os alunos entenderem a proposta teria que... eu não sei. Eu achei muito bom do jeito que a Pamela fez, porque primeiro ela ... por que que ela imprimiu? Pra primeiro passar o conceito do que é um meme, como que é a ideia!

[00:08:10.06] Maurício: não poderia dar isso aí no celular? Qual a diferença?

[00:08:14.19] Carla: eu não sei!

[00:08:15.22] Pamela: eu acho que poderia, mas eu gosto da ideia de construir um meme, mas eu não gosto da ideia... Porque, por exemplo, eu penso no meu sétimo ano que tem 35 alunos, e dai não tem espaço nem pra respirar. Aí eu não gosto da ideia de tá todo mundo no mesmo lugar, mas ao mesmo tempo não. Todo mundo tá aqui sabe [referindo-se ao celular]. Eu não gosto dessa ideia! [00:08:39.02] Maurício: por quê?

[00:08:40.29] Carla: porque não sei se eles estão de fato ali, não tem como controlar.

[00:08:43.16] Pamela: é, eu não tenho!

[00:08:44.12] Maurício: mas, por que controlar?

[00:08:45.17] Pamela: eu não quero controlar, mas a ideia é que eu não quero que eles fujam da proposta.

[00:08:49.00] Carla: é isso!

[00:08:50.10] Maurício: mas assim, quando você diz 'não quero controlar, mas não quero que eles fujam'...

[00:08:55.13] Pamela: é, dai eu tô querendo controlar.

A participante Carla, no instante [00:01:57.00], comentou que Pamela havia elaborado e desenvolvido um plano de aula utilizando memes matemáticos e, com base nisso, elas estavam planejando a atividade-matemática-com-memes para desenvolver em conjunto. Dando continuidade ao diálogo, no instante [00:02:39.23] Pamela afirma que abordou essas atividades em uma das escolas que atua e que a proposta que elas estavam 
planejando seria desenvolvida em outra escola em uma turma em que ela não havia realizado essa atividade. Assim, observamos que a participante Pamela elaborou essas atividades e, inclusive, as desenvolveu em suas turmas como um piloto para a atividade que, agora em conjunto, planejaria com seu grupo. Dessa maneira, notamos que as participantes do curso, nesse caso especialmente Pamela, estavam começando a desencadear uma possível transformação em suas práticas, de modo que estas estavam pensando, refletindo e agindo com as TD (Vanini, 2015).

Carla, então, no instante [00:04:36.01] comenta que Pamela imprimiu essas atividades para desenvolver com seus alunos e suas alunas. Complementando, Pamela no instante [00:04:48.04] relata que imprimiu e entregou para os/as estudantes. Estes/as, responderam às perguntas referentes aos memes e, então, deveriam construir um meme envolvendo algum conteúdo de matemática. Nesse contexto, percebemos que essa abordagem impressa em relação ao meme acaba contradizendo a definição de meme da internet, conforme Díaz (2013), que representa uma unidade de informação que se reproduz pela transmissão via internet na forma de uma imagem, vídeo, frase, etc. Isto é, apesar do meme, muitas vezes, ser representado por imagens ou frases estáticas ele é caracterizado como meme da internet pois ele necessita ser veiculado e compartilhado pela internet, seja por sites ou redes sociais.

Maurício, no instante [00:07:38.02], questiona a respeito de "imprimir ou usar no celular, o que vocês acham?", referindo-se à questão de como utilizar o meme na sala de aula. Carla, então, no instante [00:07:51.01] relata que gostou da maneira que Pamela desenvolveu essa atividade, refletindo "por que que ela imprimiu? Pra primeiro passar o conceito do que é um meme, como que é a ideia". Carla referia-se à definição de meme que Pamela colocou no material entregue aos estudantes: "Memes de internet é uma expressão utilizada para caracterizar uma ideia ou conceito, que se difunde através da web rapidamente. O meme pode ser uma frase, link, vídeo, site, imagem, entre outros, os quais se espalham através de e-mails, blogs, sites de notícia, redes sociais e demais fontes de informação". Notamos por essa definição utilizada por Pamela que ela considera o meme como uma unidade de informação que é transmitida pela internet, pois até definiu dessa maneira para seus alunos e suas alunas, entretanto, ela acabou utilizando de forma impressa sua atividade com memes.

Maurício no instante [00:08:10.06] questiona essa fala de Carla "não poderia dar isso ai no celular? Qual a diferença? '. Carla, no instante [00:08:14.19], afirma que não sabe a diferença e, então, Pamela no instante [00:08:15.22] fala que poderia ser no celular e que 
ela gosta da ideia de construir um meme, mas pensa em sua turma do sétimo ano com 35 alunos em que nem há espaço para respirar. Ainda nesse instante, Pamela relata que "eu não gosto da ideia de tá todo mundo no mesmo lugar, mas ao mesmo tempo não". Nesse momento, percebemos como é difícil para Pamela pensar e estar em uma aula em que "todo mundo tá aqui sabe [referindo-se ao celular]" [00:08:15.22]. Percebemos que a discussão entre Carla, Pamela e Maurício se caracteriza como um campo, pois Maurício é formador e toma como premissa a própria concepção de Cyberformação de questionar, não dar uma resposta pronta e permitir que as professoras reflitam. Assim, há uma disputa de dois movimentos em relação a um mesmo objetivo que é a discussão a respeito de imprimir ou utilizar o celular para trabalhar com a atividade. Para que um campo ocorra é preciso que existam objetos de disputas e pessoas prontas para disputar o jogo (Bourdieu, 1983).

Maurício, no instante [00:08:39.02], continua questionando e indaga o motivo dela não gostar dos estudantes estarem conectados no smartphone. Carla, no instante [00:08:40.29], responde "porque não sei se eles estão de fato ali, não tem como controlar" e Pamela, no instante [00:08:43.16], concorda com ela. Percebemos uma certa relutância das professoras em utilizar o celular, pois com o seu uso "não sei se eles estão de fato ali" e, desse modo, não há como controlar os alunos e as alunas. Notamos, assim, que Carla e Pamela se prendem nessa ideia de que é preciso entregar uma folha de atividades para os/as estudantes estarem ocupados e poder saber exatamente o que eles e elas estão fazendo para, então, ter esse controle da turma. Desse modo, percebemos um habitus dessas professoras que está ligado diretamente ao caminho realizado por elas na sociedade, em como foram suas formações e suas jornadas pessoais e profissionais, assim, esse habitus torna-se um produto que começa a ser implementado na sua história e acaba se tornando algo constituído nelas próprias (Vanini, 2015).

Continuando a discussão, Maurício no instante [00:08:44.12] argumenta "mas, por que controlar? ”. Pamela, no instante [00:08:45.17], relata que “não quero controlar, mas a ideia é que eu não quero que eles fujam da proposta”. Logo em seguida, no instante [00:08:50.10], Maurício comenta "mas assim, quando você diz 'não quero controlar, mas não quero que eles fujam'..." e, então, Pamela no instante [00:08:55.13] fala “é, daí eu tô querendo controlar”. Percebemos, então, que Pamela em um primeiro momento não acredita que quer controlar a turma, tenta até justificar que "eu não quero que eles fujam da proposta". Entretanto, Pamela acaba admitindo que sim, estava querendo controlar a turma mesmo, o que acaba evidenciando um habitus dessa professora. Essa segunda afirmação só foi possível por que Pamela foi refletindo durante a discussão guiada pelos questionamentos 
de Maurício. Assim, as intervenções de Maurício ([00:07:38.02]; [00:08:10.06]; [00:08:39.02] e [00:08:44.12]) em conjunto com a ideia de Cyberformação (apresentada aos participantes durante o quarto encontro, mas presente em todo o planejamento e desenvolvimento do curso de extensão), que acredita em uma forma/ação com professores/professoras/professories de modo a dar autonomia para eles/elas desenvolverem e produzirem suas próprias atividades e não ficarem na reprodução de materiais e ideias já prontas, caracterizaram uma violência simbólica que possibilitou essa reflexão de Pamela. Compreendemos que a Cyberformação, nesse caso, relacionando essa concepção com o curso de extensão, pode eventualmente se tornar uma violência simbólica, pois não perguntamos a esses/essas professores/professoras/professories se gostariam de aprender sobre esse constructo, mas já planejamos o curso com essa base, propondo artigos e discutindo sobre esse tema em conjunto.

Por meio dessa discussão, percebemos que a vontade de controlar seus alunos e suas alunas e, mais que isso, ter a aula toda sob controle é um habitus enraizado nessas professoras. Notamos em Carla e Pamela que, apesar de elas buscarem por formação continuada e mostrarem-se dispostas a mudanças, suas vivências e experiências passadas refletem de forma intensa em suas práticas. Nesse caso, identificamos uma tendência desse habitus se conservar em Carla e Pamela, representando uma histeresis de um habitus (Vanini, 2015).

O segundo excerto "Meme por bluetooth ${ }^{5}$ ?" ocorreu no sétimo encontro presencial em que a discussão foi gravada em vídeo, da qual foram transcritas as informações a partir do primeiro minuto e 9 segundos de gravação até os 4 minutos e 21 segundos. Esse excerto aborda a atividade-matemática-com-memes construída pelas participantes Carla e Pamela. A discussão envolve a questão de que durante o desenvolvimento da atividade foi preciso compartilhar os memes por meio do bluetooth devido à falta de internet.

\section{Meme por bluetooth?}

[00:01:09.25] Pamela: o primeiro meme que a gente mandou pra eles foi esse ai [Figura 1]. Como na escola a gente não tem... tava meio dificil o acesso à internet, então, [para] os alunos que tinham internet eu mandei no grupo que a gente fez [referindo-se ao grupo que fizeram com os alunos no WhatsApp], e dai a gente foi disseminando o meme pelo bluetooth, que era o que tinha. Dai a gente, como não tinha como trabalhar com o Whats, então eu fui fazendo as questões oralmente com eles, ai a gente os questionou se tinha algum conceito de matemática que era abordado. Se sim, qual? Eles reconheceram rapidamente, se eles tinham entendido, o que eles tinham entendido. Daí eles

\footnotetext{
${ }^{5}$ O bluetooth é uma tecnologia de comunicação sem fio que permite a troca de dados e arquivos entre smartphones. Ele utiliza uma frequência de rádio de onda curta para criar uma comunicação entre aparelhos habilitados e, por seu alcance ser curto, só permite a comunicação entre dispositivos que estão próximos (Câmara, 2012).
} 
explicaram. Aí eu perguntei o que o homem queria dizer, com aquela frase. E aí eles conseguiram entender bem.

[00:02:22.07] Pamela: né? Daí, até depois em uma das fotos tem escrito a palavra hipócrita no quadro, né? Eu perguntei: tá, e qual é o nome de uma pessoa que faz uma coisa e fala outra. Ai eles tavam lá... fiz quase um jogo da forca com eles pra eles descobrirem [a palavra].

[00:02:44.21] Carla: essa parte eu achei, assim, bem interessante, porque eu acho legal trabalhar valores e outras coisas, assim, junto com as disciplinas e na matemática. É tão difícil e ela conseguiu colocar assim, junto [com a atividade].

[...]

[00:04:19.04] Mauricio: e eles registraram essas respostas onde?

[00:04:21.19] Pamela: eles não registraram. A gente... É que, assim, eles não escreveram. Foi tudo oralmente. A ideia era fazer no Whats, né? Mas os alunos não tinham internet e a internet da escola a gente não tinha acesso.

A atividade-matemática-com-memes desenvolvida pelo grupo de Carla e Pamela envolveu questionamentos a respeito de dois memes com o assunto de potenciação e, em um segundo momento, foi proposto aos estudantes a criação de seus próprios memes. Pamela, no instante [00:01:09.25], inicia a apresentação da proposta para os/as colegas do curso relatando que elas haviam enviado o primeiro meme (Figura 1) aos alunos e como na escola estava difícil o acesso à internet elas disseminaram o meme pelo bluetooth. Desse modo, inicialmente, foi criado um grupo no aplicativo WhatsApp para trabalhar com os alunos e as alunas e a proposta inicial era enviar o meme com os questionamentos por esse grupo. Entretanto, no dia do desenvolvimento da atividade a internet disponível na escola estava com acesso restrito e, então, muitos estudantes não conseguiram acessar o grupo do WhatsApp. Uma alternativa criada para dar continuidade à atividade foi utilizar o bluetooth entre os smartphones das professoras e dos/das/des estudantes que não possuíam internet.

Figura 1 - Atividade envolvendo potenciação

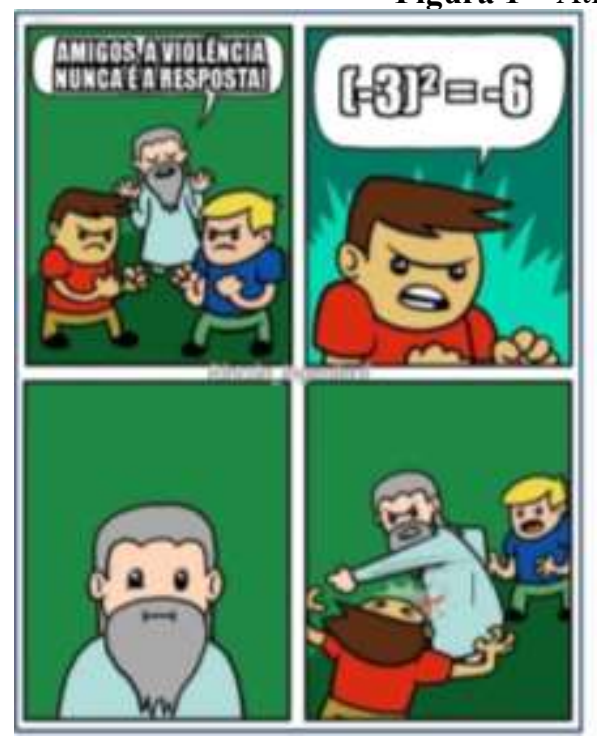

1) Hả algum conceito/conteúdo abordado no meme? Se sim, qual?

2) O que vocè entendeu desse meme? Há algum humor/piada implicito?

3) O que o homem queria dizer com "a violéncia nunca é a resposta"? Você concorda com isso? Justifique.

4) No meme o menino diz que $(-3)^{2}=-6$, como ele deve ter pensado para chegar nessa resposta? Essa resposta está correta? Justifique.

5) Podemos afirmar que o dobro de um número dá o mesmo resultado que o quadrado de um número? Por quê?

6) É possivel o quadrado de um número ter resultado negativo? Por quê?

7) O que aconteceu no último quadrinho? E qual será o motivo da reaçào do homem?

Fonte: autores

Pamela, no instante [00:04:21.19], comenta que "foi tudo oralmente. A ideia era fazer no Whats, né? ”. As participantes planejaram toda a atividade utilizando o smartphone 
e a ideia era desenvolver toda a atividade pelo WhatsApp, mas foi necessário adaptar a proposta e os questionamentos foram realizados de forma oral, bem como as respostas dos/das/des estudantes. Relembramos que no primeiro excerto (Impresso ou Digital?) essas participantes estavam discutindo a diferença de trabalhar com a atividade-matemática-commemes de forma impressa ou digital e Pamela, inicialmente, havia desenvolvido de forma impressa com seus alunos e suas alunas, pois acreditava que assim teria um maior "controle" da turma. Entretanto, apesar dos contratempos as participantes buscaram outra alternativa (bluetooth) e desenvolveram a atividade sem precisar recorrer à impressão.

Percebemos, então, que as discussões que ocorreram durante o curso de extensão, bem como as próprias concepções da Cyberformação, puderam possivelmente atuar como uma violência simbólica nessas práticas, visto que entendemos que a manutenção de um habitus é um fator forte e para que possivelmente ocorra uma alteração desse habitus é preciso haver um desequilíbrio (Bourdieu, 2009). Isto é, apesar dos contratempos, a atividade foi desenvolvida e os/as estudantes participaram da proposta como Pamela, no instante [00:01:09.25], relata que elas questionaram se havia um conceito matemático no meme e "eles reconheceram rapidamente, se eles tinham entendido, o que eles tinham entendido. Dai eles explicaram”. Assim, notamos que aquela preocupação dos/das/des estudantes fugirem da proposta da aula, como as professoras temiam (no excerto "Impresso ou Digital?”), não estava mais presente em seus discursos. Nesse contexto, percebemos que ocorreu uma possível transformação nessa prática dessas professoras, principalmente em Pamela.

Apesar de observarmos indícios de uma possível transformação nessa prática dessas professoras ressaltamos que não estamos nos referindo a transformação de um habitus, visto que para ocorrer uma transformação de um habitus é necessário um vínculo à história dessas professoras, além de uma investigação e um acompanhamento bem mais profundo de suas práticas. Então, não podemos afirmar que ocorreu uma transformação de um habitus de Pamela, por exemplo, mas podemos notar que houve indícios de rupturas de em sua prática.

\section{Considerações Finais}

Esse artigo buscou investigar indícios para responder à questão diretriz: "Como se mostra a Cyberformação com professoras que ensinam matemática, em termos pedagógicos, quando elas se inserem nos processos de produção de atividades-matemáticas-commemes?". Compreendemos que a investigação e análise do "como se mostra" a 
Cyberformação nesses processos representa apenas um recorte, uma fotografia desse contexto visto que a forma/ação nunca cessa, sempre se modifica e se transforma.

Dessa maneira, no primeiro excerto percebemos que se destacou um habitus nas práticas das professoras e que a Cyberformação associada a um curso de extensão pôde assumir um papel de violência simbólica. Já no segundo excerto, foi possível observar como o curso de extensão, como um todo, acabou atuando como uma violência simbólica para as professoras Carla e Pamela e as fizeram refletir sobre suas práticas. Nesse sentido, as práticas dessas professoras mostraram-se enraizadas em determinados habitus que quando confrontados, em um campo, com a concepção de Cyberformação permitiram uma reflexão sobre estas práticas, caracterizando uma violência simbólica e uma possível transformação de práticas.

Compreendemos, então, que as discussões e reflexões que surgiram durante o curso de extensão puderam possivelmente atuar como uma violência simbólica em professores/professoras/professories do curso, gerando um descompasso de modo que esses/essas professores/professora/professories pudessem refletir sobre suas práticas. Assim, pensando em uma forma/ação com professores/professoras/professories e entendendo as TD como partícipes da constituição do conhecimento matemático, eles e elas são estimulados e estimuladas a não reproduzirem materiais ou atividades prontas, mas sim a refletir e desenvolver suas próprias atividades e práticas de acordo com o seu respectivo contexto e sair de sua zona de conforto.

\section{Referências}

Abbagnano, N. (2007). Dicionário de Filosofia. 5 ed. São Paulo: Martins Fontes.

Bicudo, M. A. V. (2003). A formação do professor: um olhar fenomenológico. In: BICUDO, M. V. (Org.). Formação de Professores? Da incerteza à compreensão. Bauru: EDUSC.

Bourdieu, P. (1983). Questões de Sociologia. Rio de Janeiro: Marco Zero.

Bourdieu, P. (2009). O Senso Prático. Tradução: Maria Ferreira. Rio de Janeiro: Vozes.

Bourdieu, P. (2012). O Poder Simbólico. Tradução: Fernando Tomaz. 16 ed. Rio de Janeiro: Bertrand Brasil.

Bourdieu, P. \& Passeron, J. C. (2014). A Reprodução: elementos para uma teoria do sistema de ensino. Tradução: Reynaldo Bairão. 7 ed. Petrópolis: Vozes.

Câmara, M. (2012). Bluetooth: O que é e como funciona. Techtudo. Disponível em: https://www.techtudo.com.br/artigos/noticia/2012/01/bluetooth-o-que-e-e-comofunciona.html. Acesso em: 24 de fev. de 2021. 
Cassiano, O. (2019). Guia para "Linguagem Neutra" (PT-BR). Disponível em: https://medium.com/guia-para-linguagem-neutra-pt-br/guia-para-linguagem-neutrapt-br-f6d88311f92b. Acesso em: 20 jun. 2021.

Díaz, C. M. C. (2013). Defining and characterizing the concept of Internet Meme. Revista CES Psicología, v. 5, n. 2, p. 82-104, jul/dez.

Dicio. (2021). Dicionário online de português. Disponível em: https://www.dicio.com.br. Acesso em: 23 de fev. de 2021.

Friske, A. L. (2020). Memes e Matemática: a formação com professores/as na perspectiva da Cyberformação. Dissertação (Mestrado em Ensino de Matemática) Universidade Federal do Rio Grande do Sul, Porto Alegre.

Goldenberg, M. (2004). A arte de pesquisar: como fazer pesquisa qualitativa em Ciências Sociais. 8 ed. Rio de Janeiro: Editora Record.

Harringhton Martínez, M. S., Díaz Blanca, L. Ángela, \& Bolívar Orellana, A. C. (2020). Representaciones Sociales de la Tesis Reflejadas em los Memes. Paradigma, 837863. https://doi.org/10.37618/PARADIGMA.1011-2251.2020.p837-863.id824

Pazuch, V. (2014). Cyberformação semipresencial: A relação com o saber de professores que ensinam matemática. Tese (Doutorado em Ensino de Ciências e Matemática) Universidade Luterana do Brasil, Canoas.

Rosa, M. (2015). Cyberformação com Professores de Matemática: interconexões com experiências estéticas na cultura digital. In: ROSA, M.; BAIRRAL, M. A.; AMARAL, R. B. Educação Matemática, Tecnologias Digitais e Educação a Distância: pesquisas contemporâneas. São Paulo: Editora Livraria da Física, p. $57-$ 93.

Rosa, M. (2018). Tessituras teórico-metodológicas em uma perspectiva investigativa na Educação Matemática: da construção da concepção de Cyberformação com professores de matemática a futuros horizontes. In.: OLIVEIRA, A. M. P.; ORTIGÃO, M. I. R. (Org.). Abordagens teóricas e metodológicas nas pesquisas em Educação Matemática. Brasília: Sociedade Brasileira de Educação Matemática. Ebook.

Rosa, M. (no prelo). A Responsabilidade Social na Cyberformação com Professories de Matemática: uma questão de raça? In.: ROSA, M.; NETO, V. SEMINÁRIO INTERNACIONAL DE PESQUISA EM EDUCAÇÃO MATEMÁTICA, 8., 2021, Uberlândia. Anais... Brasília: SBEM.

Rosa, M. (n.d.). Cyberformação com professories de matemática: a compreensão da héxis política à pedagogia queer. In. ESQUINCALHA, A. C. Estudos de Gênero e Sexualidades em Educação Matemática: tensionamentos e possibilidades. Brasília: SBEM, 2022. Ebook.

Rosa, M. \& Mussato, S. (2015). Atividade-matemática-com-tecnologias-digitais e Contextos Culturais: investigando o design como processo de Cyberformação com professores de matemática. Jornal Internacional de Estudos em Educação Matemática - JIEEM. São Paulo: UNIBAN, v.8, n.4, p.23-42.

Vanini, L. (2015). A Construção da Concepção da Cyberformação por Professores e Tutores de Matemática Online na Formação Continuada e na sua Prática: uma análise bourdieana. Tese (Doutorado em Ensino de Ciências e Matemática) Universidade Luterana do Brasil, Canoas. 
Vanini, L.; Rosa, M.; Justo, J. C. R. \& Pazuch, V. (2013). Cyberformação de Professores de Matemática: olhares para a dimensão tecnológica. Acta Scientiae, Canoas, v. 15, n. 1, p. 153-171, jan/abr.

\section{Autores}

Andréia Luisa Friske

Mestre em Ensino de Matemática pela Universidade Federal do Rio Grande do Sul UFRGS (2020). Graduada em Matemática Licenciatura Plena pela Universidade Federal de Santa Maria - UFSM (2017). Atualmente é professora na Secretaria de Educação do Estado do Rio Grande do Sul e atua como professora voluntária no curso do software matemático GeoGebra (www.ogeogebra.com.br/cursos) ministrado na modalidade online e ofertado pela Universidade Estadual do Paraná. andreiafriske@gmail.com https://orcid.org/0000-0002-1977-129X

Maurício Rosa

Doutor em Educação Matemática pela Universidade Estadual Paulista Júlio de Mesquita Filho - Unesp - Rio Claro (SP) (2008). Mestre em Educação Matemática pela Universidade Estadual Paulista Júlio de Mesquita Filho - Unesp - Rio Claro (SP) (2004). Graduado em Matemática Licenciatura Plena pela Universidade Luterana do Brasil - ULBRA - Canoas (RS) (2001/2). Foi bolsista do programa de Doutorado com Estágio no Exterior - PDEE pela Coordenação de Aperfeiçoamento de Pessoal de Nível Superior - CAPES, sob o processo BEX - 3899/06-3, na London South Bank University - Londres (UK). Coordenou o Grupo de Pesquisa @ + (AMAIIS- Ambientes-Matemáticos de Aprendizagem com a Inclusão da Informática na Sociedade) de março de 2008 a julho de 2014. Participa do grupo de pesquisa FEM (Fenomenologia e Educação Matemática http://dgp.cnpq.br/dgp/espelhogrupo/6283479768168094), desde 2008 e atualmente participa de um projeto internacional com o Prof. Danyal Farsani sobre cognição corporifica com Tecnologias Digitais (Agência Nacional de Pesquisa e Desenvolvimento do Chile ANID / PAI 77200008). Foi coordenador do Grupo de Trabalho (GT06) Educação Matemática: Novas Tecnologias e Educação a Distância da Sociedade Brasileira de Educação Matemática (SBEM), de 2009 a 2012 e voltou a coordenar esse grupo no período de 2018 a 2019. Foi $2^{\circ}$ secretário da SBEM - Regional do Rio Grande do Sul de 2009 a 2012 e diretor dessa regional de 2012 a 2015. Atualmente, é terceiro secretário da Sociedade Brasileira de Educação Matemática - SBEM (2019-2022) e editor da Revista Internacional de

Pesquisa em Educação Matemática (RIPEM). Atua como professor da Faculdade de Educação da Universidade Federal do Rio Grande do Sul, Departamento de Ensino e Currículo, e do Programa de Pós-Graduação em Ensino de Matemática do Instituto de Matemática dessa Universidade. mauriciomatematica@gmail.com https://orcid.org/0000-0001-9682-4343

\section{Como citar este Artículo:}

FRISKE, A. L.; ROSA, M. Cybereducación: Discutir el Habitus de los Professores en un Contexto de Producción de Actividades-Matemáticas-Con-Memes. Revista Paradigma Vol. XLII, Nro. 2, Diciembre de 2021 / 206 - 225. DOI:

10.37618/PARADIGMA.1011-2251.2021.p206-225.id1107 